\title{
Bifidobacterium infantis strains with and without a combination of Oligofructose and Inulin (OFI) attenuate inflammation in DSS-induced colitis in rats
}

\author{
Nadia Osman ${ }^{1}$, Diya Adawi*2, Göran Molin ${ }^{1}$, Siv Ahrne ${ }^{1}$, Anna Berggren ${ }^{3}$ \\ and Bengt Jeppsson ${ }^{2}$
}

Address: ${ }^{1}$ Dept of Food Technology, Engineering and Nutrition, Lund University, Sweden, ${ }^{2}$ Dept of Surgery University Hospital Malmö, Lund University, 20502 Malmö, Sweden and PProbi AB, Lund, Sweden

Email: Nadia Osman - nadia.osman@food.lth.se; Diya Adawi* - diya.adawi@med.lu.se; Göran Molin - goran.molin@food.lth.se; Siv Ahrne - siv.ahrne@food.lth.se; Anna Berggren - anna.berggren@probi.se; Bengt Jeppsson - bengt.jeppsson@med.lu.se

* Corresponding author

Published: 28 October 2006

BMC Gastroenterology 2006, 6:31 doi:|0.II86/I47|-230X-6-3 |
Received: 19 June 2006

Accepted: 28 October 2006

This article is available from: http://www.biomedcentral.com/I47I-230X/6/3।

(C) 2006 Osman et al; licensee BioMed Central Ltd.

This is an Open Access article distributed under the terms of the Creative Commons Attribution License (http://creativecommons.org/licenses/by/2.0), which permits unrestricted use, distribution, and reproduction in any medium, provided the original work is properly cited.

\begin{abstract}
Background: Pathogenesis of inflammatory bowel disease is thought to be through different factors and there is a relationship between the gut flora and the risk of its development. Probiotics can manipulate the microflora in chronic inflammation and may be effective in treating inflammation. Bifidobacterium are saccharolytic and their growth in the gut can be promoted by non-absorbable carbohydrates and its increase in the colon appears to be of benefit.
\end{abstract}

Methods: Oligofructose and inulin (OFI) alone and the two B. infantis DSM I5I58 and DSM I5I59 with and without OFI, were fed to Sprague-Dawley rats for 7 days prior to colitis induction and administrations continued for another 7 days with the DSS. Colitis severity assessed using a Disease Activity Index. Samples were collected 7 days after colitis induction, for intestinal bacterial flora, bacterial translocation, short chain fatty acids (SCFAs), myeloperoxidase (MPO), cytokines (IL-I $\beta$, TNF- $\alpha$, IL- 10 and TGF- $\beta$ ) and malondialdehyde (MDA).

Results: OFI alone or the $B$. infantis strains with and without OFI improved significantly the DAI and decreased colonic MPO activity. Colonic tissue IL-I $\beta$ decreased significantly in all treated groups except $B$. infantis DSM I5I58. MDA decreased significantly in B. infantis DSM 15159 with and without OFI compared to colitis control. Succinic acid increased significantly in OFI group with and without DSM 15159 compared to all groups. Sum values of propionic, succinic acid and butyric acid increased significantly in all groups compare to the colitis control. Bacterial translocation to mesenteric lymph nodes decreased significantly in all groups compared to colitis control. Translocation to the liver decreased significantly in all groups compare to the colitis control and OFI + B. infantis DSM I5I58 groups.

Conclusion: Administrations of OFI and Bifidobacterium improve DSS-induced acute colitis and have an anti-inflammatory effect. Major differences in effect were observed between the two $B$. infantis strains as indicated in MDA and succinic acid concentration as well as bacterial translocation rate in synbiotic combinations. 


\section{Background}

The pathogenesis of inflammatory bowel disease is thought to involve different factors. The intestinal mucosal immune system has the formidable task of remaining unresponsive to the vast indigenous bacterial population, and yet be able to discriminate and eliminate pathogenic microorganisms to control infection. Studies in rodent models $[1,2]$, suggest that abnormalities in this immuno-bacterial relationship may be a key to the pathogenesis of the human IBD, ulcerative colitis and Crohn's disease.

Although not one pathogenic factor has been established, relationship between the establishment of the gut flora and the risk of developing inflammatory bowel disease (IBD) has been suggested [3]. In IBD evidence has been found for a disturbed balance between pro-inflammatory and anti-inflammatory cytokines. Increased levels of the proinflammatory cytokines interleukin-1 (IL-1), IL-6, IL8 , and tumor necrosis factor $\alpha$ (TNF- $\alpha$ ) were detected [4]. The cytokines are secreted by macrophages, lymphocytes, and polymorphonuclear neutrophils (PMNs) and the massively infiltrating of these cells are thought to contribute by producing large amounts of reactive oxygen metabolites (ROMs), such as superoxide anion, hydrogen peroxide, and hypochlorous acid [5].

Probiotics (micro-organism such as bifidobacteria and lactobacilli with purported physiological benefits) are being evaluated as an alternative means of manipulating the microflora in chronic inflammation. Laboratory studies have shown that probiotics (mainly lactobacilli) may be effective in treating inflammation [6-8]. Much less focus has been on bifidobacteria because of cost and maintenance of viability. In vitro, growth of bifidobacteria can be selectively stimulated by several carbohydrates indigestible by humans (prebiotics). In particular, the fructans inulin and oligofructose seem effective at stimulating growth of bifidobacteria selectively in vitro [9]. Consumption of both probiotic bacteria [10], and prebiotic components [11], reduces the severity of DSSinduced colitis.

To clarify the effects and the mechanisms behind we therefore investigate the efficacy of oral supplementation of Bifidobacterium infantis and oligofructose and inulin (OFI) as a primary prevention and therapy of colitis. We wanted especially to focus on effects on bacterial translocation, bacterial flora, inflammation, release of oxygen free radicals and bacterial fermentation.

\section{Methods}

Animals and experimental design

Sprague-Dawley rats (200 g) (Möllegård, Viby, Denmark) were used and divided into six groups (6 animals each), colitis control and five treatment groups. One group was treated with a commercially available preparation of oligofructose and inulin (OFI) (Raftilose Synergy 1, Orafti Active Food ingredients, Tienen, Belgium). This contains inulin with selected chain lengths from chicory that has been enriched by a specific fraction of oligofructose produced by partial enzymatic hydrolysis of chicory inulin. Four groups were treated with Bifidobacterium infantis ( $B$. infantis DSM 15158 [= CURE19] or B. infantis DSM 15159 [= CURE21], Probi AB, Lund, Sweden) alone or together with OFI. The two B. infantis strains have been isolated from infant feces, and have been selected for their colonization capabilities and abilities to produce amino acids from inorganic nitrogen. The animals were kept at room temperature $\left(22^{\circ} \mathrm{C}\right)$ with a controlled $12 \mathrm{hr}$ light/dark cycle and free access to a standard rat chow (R3; Lactamin, Stockholm). The experimental solutions were administered orally by oro-gastric tube twice daily for 7 days before starting DSS and continued for 7 days after DSS induction (probiotics $3 \mathrm{ml} ; 3 \times 10^{6} \mathrm{CFU}$ per animal, prebiotics $3 \mathrm{ml}$; $0.5 \mathrm{~g}$ per animal, synbiotics $3 \mathrm{ml} ; 3 \times 10^{6} \mathrm{CFU}$ $+0.5 \mathrm{~g}$ per animal). Normal saline $(3 \mathrm{ml})$ was administered in the colitis control group. Colitis was induced by $5 \%(\mathrm{w} / \mathrm{v})$ DSS (MW = 36,000-50,000; ICN Biomedicals Inc., Aurora, $\mathrm{OH}$ ) dissolved in drinking water for 7 days. Severity of colitis was assessed daily using a disease activity index (DAI). After the seventh day of induction of colitis, animals were anesthetized with a subcutaneous injection of a mixture (1:1:2) of Hypnorm (Division of Janssen-Cilag Ltd., Janssen Pharmaceutica, Beerse, Belgium) + Dormicum (F. Hoffmann-La Roche AG, Basel, Switzerland) $+\mathrm{dH}_{2} \mathrm{O}$ at a dose of $0.15 \mathrm{ml} / 100 \mathrm{~g}$. Under aseptic technique a laparotomy was performed through a midline incision and samples were collected for bacterial microflora (cecum), bacterial translocation (arterial and portal blood, mesenteric lymph nodes, and liver), SCFAs (cecal contents), Myeloperoxidase (MPO), cytokines (IL$1 \beta$, TNF- $\alpha$, IL-10 and TGF- $\beta$ ) and Malondialdehyde (MDA) (colon tissues). Bacterial microflora samples were placed immediately in sterile tubes containing, $3 \mathrm{ml}$ of transport medium, whereas bacterial translocation samples were placed in sterile tubes containing, $2 \mathrm{ml}$ for blood, and, $6 \mathrm{~m} 1$ for segments [12]. Samples for cytokines, MPO, MDA, and SCFAs were immediately frozen at $-70^{\circ} \mathrm{C}$. The experimental design was approved by the Animal Ethics Committee of Lund University and the experiments adhered to the guiding principles in the care and use of animals.

\section{Assessment of colitis}

The severity of colitis was assessed daily using a Disease Activity Index (DAI) based on the scoring system of Murthy et al. $[13,14]$, which scores body weight loss, stool consistency, and rectal bleeding. Occult blood in feces was evaluated by means of test slides, Hemoccult II (SmithK- 
line Diagnostic, USA). The DAI clinical parameters used here are comprehensive functional measures that are somewhat analogous to clinical symptoms observed in human IBD and the scoring method has been validated by repeated studies [15].

\section{Bacterial translocation}

Samples from the caudate lobe of liver, mesenteric lymph nodes, portal and arterial blood were placed in an ultrasonic bath (Millipore, Sundbyberg, Sweden) for $5 \mathrm{~min}$ and swirled on Chiltern (Therma-Glas, Gothenberg, Sweden) for $2 \mathrm{~min}$. Viable counts were obtained from brain heart infusion (BHI) agar (Difco, Detroit, MI) that was incubated aerobically and under anaerobic condition (Gas Pack System, Gas Pack; Becton Dickenson Microbiology Systems, Cockeynsville, MD) at $37^{\circ} \mathrm{C}$ for $72 \mathrm{~h}$ (aerobic and anaerobic bacterial count, respectively). Violet-red bile glucose (VRBG) agar (Oxoid) was incubated aerobically at $37^{\circ} \mathrm{C}$ for $24 \mathrm{~h}$ (Enterobacteriaceae count). The number of colonies formed on each plate was counted and corrected for the weight of the original tissue and volume of blood. Tissue samples are expressed per gram of tissue while blood samples are expressed per milliliter of blood.

\section{Intestinal microflora}

The samples from the cecum were placed in an ultrasonic bath and swirled on Chiltern as above. A conventional dilution procedure was done. Viable counts were obtained from BHI agar that was incubated aerobically and anaerobically at $37^{\circ} \mathrm{C}$ for $72 \mathrm{~h}$ (aerobic and anaerobic bacterial count, respectively), Rogosa agar (Oxoid) that was incubated anaerobically at $37^{\circ} \mathrm{C}$ for $72 \mathrm{~h}$ (lactobacilli count), from VRBG agar (Oxoid) that was incubated aerobically at $37^{\circ} \mathrm{C}$ for $24 \mathrm{~h}$ (Enterobacteriaceae count), and from the selective media, Modified Wilkins-Chalgren agar (MW; Oxoid), Modified Trypticase phytone-yeast extract agar (MTPY; ACSA, Spain) [16] and non-strictly selective Basic nutrient-poor media [17], which was modified according to the following composition per liter, (sodium acetate $10 \mathrm{~g}$ : ascorbic acid $10 \mathrm{~g}$ : $\left(\mathrm{NH}_{4}\right)_{2} \mathrm{SO}_{4} 5 \mathrm{~g}: \mathrm{K}_{2} \mathrm{HPO}_{4} 3$ $\mathrm{g}$ : $(\mathrm{KH})_{2} \mathrm{PO}_{4} 3 \mathrm{~g}$ : tween $801 \mathrm{ml}$ : yeast extract $0.5 \mathrm{~g}$ : glucose $20 \mathrm{~g}$ : agar $15 \mathrm{~g}$ and $5 \mathrm{ml}$ of the mineral salt solution which composed per $250 \mathrm{ml}$ of $\left(\mathrm{MgSO}_{4} \cdot 7 \mathrm{H}_{2} \mathrm{O} \quad 16 \mathrm{~g}\right.$ : $\left.\mathrm{FeSO}_{4} \cdot 7 \mathrm{H}_{2} \mathrm{O} 0.5 \mathrm{~g}: \mathrm{MnSO}_{4} \cdot \mathrm{H}_{2} \mathrm{O} 0.35 \mathrm{~g}: \mathrm{NaCl} 0.5 \mathrm{~g}\right) \mathrm{pH}$ 6.18-6.24. They were incubated under anaerobic conditions at $37^{\circ} \mathrm{C}$ for $72 \mathrm{~h}$ (bifidobacteria count).

\section{Cytokines}

Samples of colon were weighed and homogenized for 1 min in phosphate buffer. The homogenates were centrifuged at $10000 \mathrm{~g}$ at $4{ }^{\circ} \mathrm{C}$ for $5 \mathrm{~min}$. TNF- $\alpha$, IL- $1 \beta$, IL-10 and TGF- $\beta$ concentration in the supernatants were determined by ELISA using the commercially available Quantikine kit (R\&D Systems, Minneapolis, MN 55413, USA).
Optical densities were measured on an ELISA reader at a wavelength of $450 \mathrm{~nm}$. Data were analyzed against the linear portion of the generated standard curve.

\section{Myeloperoxidase (MPO)}

Colonic tissues were collected, weighed prior to storage at $-70^{\circ} \mathrm{C}$ until time of assay for MPO activity. The colonic segments were homogenized in $1 \mathrm{ml}$ potassium phosphate buffer ( $20 \mathrm{mM}, \mathrm{pH} 7.4)$ for $60 \mathrm{sec}$. Subsequently, the homogenate was centrifuged $(14000 \mathrm{rpm}, 10 \mathrm{~min})$ and the pellet was resuspended in $1 \mathrm{ml}$ potassium phosphate buffer $(50 \mathrm{mM}, \mathrm{pH} 6.0)$ containing $0.5 \%$ hexadecyltrimethyl-ammonium bromide. The sample was then freeze thawed once, sonicated (90 sec) and kept in water bath for $120 \mathrm{~min}\left(60^{\circ} \mathrm{C}\right)$. Next, the sample was centrifuged (14000 rpm, $10 \mathrm{~min})$ and the MPO activity of the supernatant $(20 \mu \mathrm{l})$ assessed in 96-well plates (Nunc, Invitrogen A/S, Taastrup, Denmark). The enzyme activity was determined spectrophotometrically at $450 \mathrm{~nm}$. MPO (Sigma Chemical Co., St. Louis, MO, USA) was used as standard and values are expressed as MPO units $\mathrm{g}^{-1}$ tissue.

\section{Lipid peroxidation}

Malondialdehyde (MDA) were determined as index of lipid peroxidation, using MDA $586^{\mathrm{TM}}(\mathrm{R} \& \mathrm{D}$, Europe Ltd, Abingdon, Oxon, UK). Colonic segments were collected, rinsed in ice cold Dulbecco's PBS, weighed and then frozen immediately at $-70^{\circ} \mathrm{C}$ for later evaluation. Lipid peroxidation was estimated by adding $1 \mathrm{ml}$ Dulbecco's PBS with $5 \mathrm{mM}$ butylated-hydroxyltoluene to the samples and then homogenized. After homogenization the samples were centrifuged at $4000 \times \mathrm{g}$ for 10 minutes $(\mathrm{min})$ at $4{ }^{\circ} \mathrm{C}$. An aliquot $(200 \mu \mathrm{l})$ of the standard and/or the supernatant was added to a reaction mixture containing $640 \mu \mathrm{l}$ of $\mathrm{N}$-methyl-2-phelindole, $10 \mu \mathrm{l}$ probucol and $150 \mu \mathrm{l}$ of 12 $M$ hydrochloric acid. The samples were then incubated in a water bath for $60 \mathrm{~min}$ at $45^{\circ} \mathrm{C}$ and centrifuged at 10000 $\times \mathrm{g}$ for $10 \mathrm{~min}$ at $4^{\circ} \mathrm{C}$. The absorbance of the standard and supernatant was measured by Spectrophotometry at 586 $\mathrm{nm}$. The results were expressed as nmol MDA/g tissue.

\section{Short Chain Fatty Acids (SCFAs)}

SCFAs and organic acids (lactic, and succinic, acid) were measured by a modification of the capillary GC method by Richardson et al. [18] as described by Jensen et al. [19]. Sample preparation was done by diluting 10 times the cecal content samples with a working solution containing water and internal standard (IS) $(100 \mathrm{mmol} / \mathrm{l} 2$-Ethylbutyric acid). The diluted sample was homogenized and a 1 $\mathrm{ml}$ sub-sample was taken for extraction. This sample was extracted by adding $0.1 \mathrm{ml} \mathrm{H}_{2} \mathrm{O}, 500 \mu \mathrm{l}$ hydrochloric acid $(\mathrm{HCl})$ and $2000 \mu \mathrm{l}$ ether followed by mixing for $30 \mathrm{sec}-$ onds on a Vibrax at $1400 \mathrm{rpm}$, and centrifugation for 10 $\mathrm{min}$ at $3000 \mathrm{~g}$. For every 8 samples, 2 standard mixtures were prepared by adding $0.1 \mathrm{ml} \mathrm{H}_{2} \mathrm{O}, 0.5 \mathrm{ml} \mathrm{HCl}, 100 \mu \mathrm{l}$ 
working solution and $2000 \mu \mathrm{l}$ ether to a $1 \mathrm{ml}$ standard mixture. To the GC microvial was added $50 \mu$ l sample and/or standard from the ether-phase together with $10 \mu \mathrm{l}$ N-tert-butyldimethylsilyl-N-trifluoroacetamid, to derivatize the samples and get volatile and thermal constant derivatives that are suitable for GC run. The vial with Crimp-Caps were closed and mixed once and placed on the $80^{\circ} \mathrm{C}$ heating block for 20 minutes. To complete the derivatisation, the samples were allowed to stand 48 hours before injection. The analysis was performed using a gas chromatograph provided with capillary column (DB-5, J\&W Scientific, USA). The following temperatureprogram were used $\left(70^{\circ} \mathrm{C}(3 \mathrm{~min}), 70-110^{\circ} \mathrm{C}\left(10^{\circ} \mathrm{C} /\right.\right.$ $\min ), \quad 110-270^{\circ} \mathrm{C}\left(20^{\circ} \mathrm{C} / \mathrm{min}\right)$. Detector and injector temperature were 275 and $300^{\circ} \mathrm{C}$, respectively, and the carrier gas was helium $(1.9 \mathrm{ml} / \mathrm{min}) .2 \mu \mathrm{l}$ sample volume was injected.

\section{Statistics}

Values are presented as mean \pm SEM or as median (10th, 25th, 75th, and 90th percentiles). For the DAI the difference between the groups was evaluated using KruskalWallis one-way ANOVA on ranks followed by all-pairwise multiple comparison procedures (Student-NewmanKeuls Method). Bacterial translocations and intestinal microflora were evaluated by one-way ANOVA followed by all-pairwise multiple comparison procedures (StudentNewman-Keuls Method). For cytokines, MPO, and MDA the difference between the groups was evaluated using one-way ANOVA followed by multiple-comparison versus control-group Dunnett's method. Probability levels of $<0.05$ were considered significant $(p<0.05)$.

\section{Results}

\section{Assessment of disease activity index DAI}

There was no mortality among the experimental groups. DAI decreased significantly on day 4 \& 5 (data not shown) and day $6 \& 7$ in all groups compared to colitis control group (Figure 1).

\section{Bacterial translocation}

Bacterial translocation to the liver decreased significantly in all the groups compared to colitis control and OFI $+B$. infantis DSM 15158 groups (Table 1). Bacterial translocation to the mesenteric lymph nods decreased significantly in all the groups compared to colitis control (Table 1).

\section{Intestinal bacterial flora}

The bifidobacterial counts in cecum (using 2 selective media) increased significantly in the OFI groups with and without added B. infants compared to colitis control (8.74 $\pm 0.07,8.89 \pm 0.16,8.32 \pm 0.50$ versus $6.82 \pm 0.37$ for the modified Wilkins-Chalgren agar) and $(8.73 \pm 0.07,8.60 \pm$ $0.19,8.23 \pm 0.48$ versus $6.57 \pm 0.37$ for the modified Trypticase phytone-yeast extract agar). For the not strictly selec- tive media it increased significantly in all groups compared to colitis control (Data not shown). There were no differences in the cecum Enterobacteriaceae count. The cecal count of lactobacilli increased significantly in $B$. infantis DSM 15159 groups with and without OFI (8.85 \pm 0.24 and $9.56 \pm 0.05$ respectively) compared to colitis control $(7.82 \pm 0.47)$.

\section{Myeloperoxidase (MPO)}

Colonic myeloperoxidase activity decreased significantly in all groups compared to the colitis control group (Figure 2).

\section{Cytokines}

Colonic tissue IL-1 $\beta$ decreased significantly in all treated groups except $B$. infantis DSM 15158 (Figure 3), while levels of TGF- $\beta$ and IL-10 were maintained in all groups without significant difference (data not shown). There was no detection of TNF- $\alpha$ in any of the groups.

\section{Lipid peroxidation}

MDA decreased significantly in the B. infantis DSM 15159 groups with and without OFI compared to colitis control (Figure 4).

\section{Short-Chain Fatty Acids (SCFAs)}

Succinic acid increased significantly in the OFI groups with and without DSM 15159 compared to the control and other groups (Table 2). Sum values of propionic and butyric acid increased significantly in all treated groups [5.9 (3.9-7.3), 6.1(4.1-8.6), 4.7(3.3-6.5), 5.7(4.5-6.4), 6.4(4.6-10.1)] compare to the colitis control group [3.2(2.3-3.8)]. Sum values of succinic, propionic and butyric acids also increased significantly in all treated groups $[5.4(3.6-7.0), 4.1(0.0-6.6), \quad 3.3(1.6-5.2)$, $4.9(3.0-5.8), 6.0(4.0-10.0)]$ compare to the colitis control group [2.6(0.0-3.3)], but the OFI + B. infantis DSM 15159 was significantly higher $[6.0(4.0-10.0)]$ than in all other groups.

\section{Discussion}

Daily oral administration of Bifidobacteria, oligufructose and inulin produced an anti-inflammatory effect in a rat model of acute colitis induced by DSS. The effect of OFI, B. infantis DSM 15158 and B. infantis DSM 15159 both separately and in combination were characterized by a reduction in DAI. It has previously been shown in a pilot study that short term treatment of active UC with bifidobacterium longum and Synergy 1 resulted in improvement of chronic inflammation in patients [20]. The results of that study dose not evaluate production of SCFA or if the different bifidobacteria have similar action. We have chosen Bifidobacterium infantis, which was isolated from feces of healthy infants. We believe that the bacterial strains that are colonizing gut of the newborn infant have specific 


\section{Day 6}

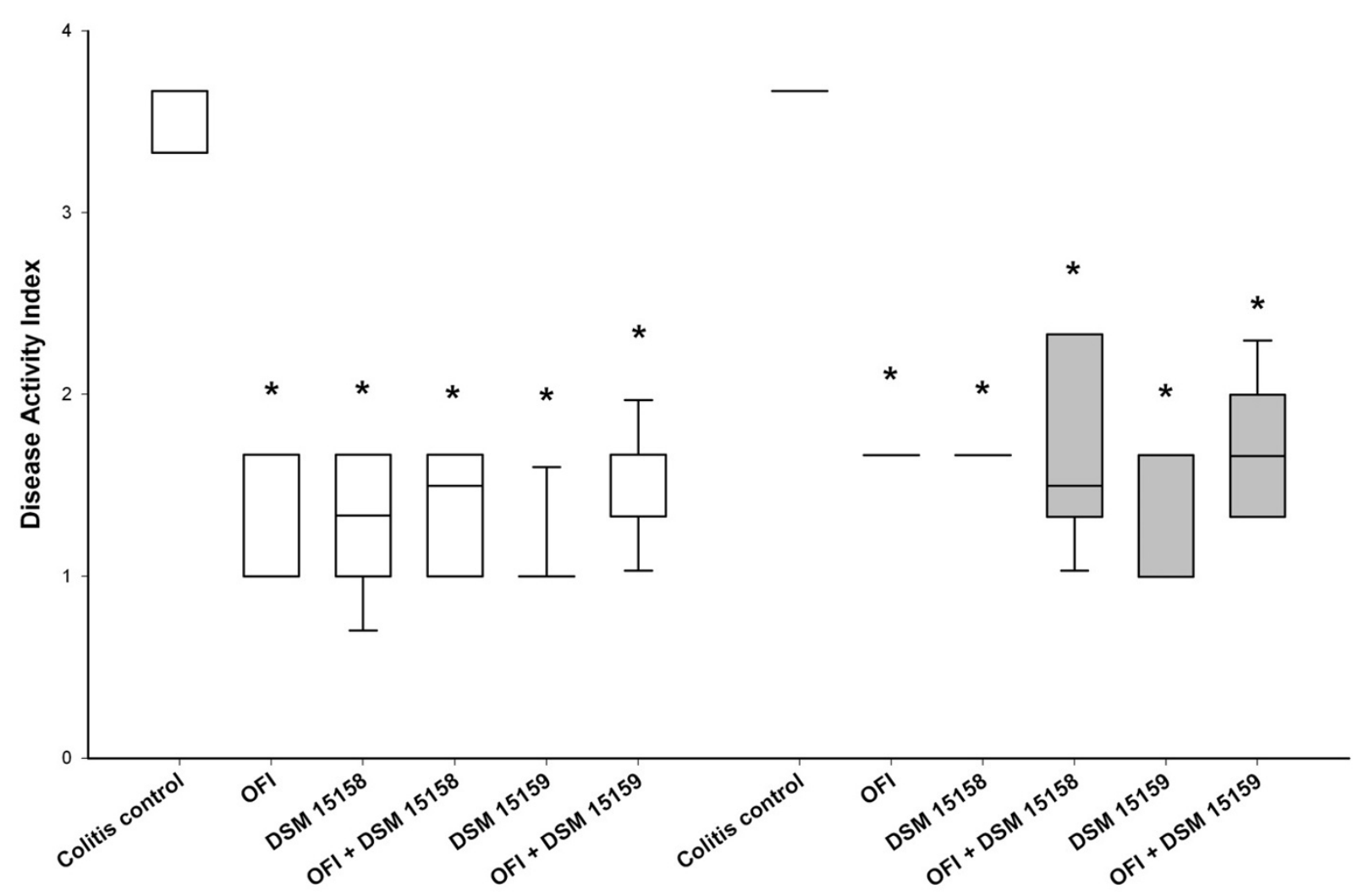

\section{Figure I}

Disease activity index on day 6 and 7. Values are shown as box plots because the data were not normally distributed. The center line of each box represents the median, the top and bottom of the boxes represent the 25 th and 75 th percentile of the data, respectively, and the top and the bottom of the error bars represent the 10 th and the 90 th percentile of the data respectively. $*$ denotes $\mathrm{p}<0.05$ compared to colitis control.

characteristics that may also benefit adult mucosa that is under inflammatory stress.

Both bacteria as well as the fiber component were effective in reducing colonic disease activity index, although DSM 15159 seemed superior. The same holds true for bacterial translocation where DSM 15159 was superior in reducing bacterial translocation to both liver and mesenteric lymph nodes in synbiotic combination. We found that tissue MPO activity as an index of neutrophil infiltration significantly reduced in all groups compare to the colitis control. However, the observed anti-inflammatory effect may have been reached through different mechanisms.
The increase of IL-1 $\beta$ in the colitis group was significantly decreased in all groups except in the B. infantis DSM 15158 group. The expression of IL-1 is increased in inflammatory lesions of patients with IBD (4) and IL-1 is involved in the development of DSS-induced colitis in mice [21]. The reduction of IL-1 $\beta$ could be achieved through different ways. Incubation of mucosal explants from Crohn's disease patients showed that certain probiotic bacteria are capable of interacting with immunocompetent cells and modulate locally the production of proinflammatory cytokines by inflamed tissue [22]. A human epithelial cell line HT29/19A, which produces the chemokines IL-8, upon stimulation with IL-1, TNF and interferon when incubated with bacterial cell suspensions showed that Gram-positive probiotic bacteria did not 
Table I: Bacterial translocation count to the liver and mysenteric lymph nodes (MLNs) (log CFU/g tissue) and Incidence of translocation

\begin{tabular}{|c|c|c|c|}
\hline & Aerobic & Anaerobic & Enterobacteriaceae \\
\hline \multicolumn{4}{|l|}{ Liver } \\
\hline$\overline{\text { Colitis control }}$ & $2.72 \pm 0.77(4 / 6)$ & $3.58 \pm 0.33(5 / 6)$ & $1.89 \pm 0.66(4 / 6)$ \\
\hline OFI & $0.38 \pm 0.38 * \#(1 / 6)$ & $0.50 \pm 0.50 * \#(1 / 6)$ & $0.00 \pm 0.00 * \#(0 / 6)$ \\
\hline DSM 15158 & $0.00 \pm 0.00 * \#(0 / 6)$ & $0.00 \pm 0.00 * \#(0 / 6)$ & $0.00 \pm 0.00 * \#(0 / 6)$ \\
\hline OFI + DSM I5I58 & $3.14 \pm 1.01(4 / 6)$ & $3.29 \pm 1.06(4 / 6)$ & $2.98 \pm 0.73(4 / 6)$ \\
\hline DSM I5I59 & $0.55 \pm 0.55 * \#(1 / 6)$ & $0.57 \pm 0.57 * \#(1 / 6)$ & $0.00 \pm 0.00 * \#(0 / 6)$ \\
\hline OFI + DSM I5I59 & $0.00 \pm 0.00 * \#(0 / 6)$ & $0.00 \pm 0.00 * \#(0 / 6)$ & $0.00 \pm 0.00 * \#(0 / 6)$ \\
\hline \multicolumn{4}{|l|}{ MLNs } \\
\hline Colitis control & $2.61 \pm 0.76(4 / 6)$ & $2.71 \pm 0.80(4 / 6)$ & $1.73 \pm 0.73(3 / 6)$ \\
\hline OFI & $0.00 \pm 0.00 *(0 / 6)$ & $0.00 \pm 0.00 *(0 / 6)$ & $0.00 \pm 0.00 *(0 / 6)$ \\
\hline DSM 15158 & $0.00 \pm 0.00 *(0 / 6)$ & $0.00 \pm 0.00 *(0 / 6)$ & $0.00 \pm 0.00 *(0 / 6)$ \\
\hline OFI + DSM I5I58 & $0.48 \pm 0.48 *(1 / 6)$ & $0.00 \pm 0.00 *(0 / 6)$ & $0.00 \pm 0.00 *(0 / 6)$ \\
\hline DSM I5I59 & $0.00 \pm 0.00 *(0 / 6)$ & $0.00 \pm 0.00 *(0 / 6)$ & $0.00 \pm 0.00 *(0 / 6)$ \\
\hline OFI + DSM 15159 & $0.00 \pm 0.00 *(0 / 6)$ & $0.00 \pm 0.00 *(0 / 6)$ & $0.00 \pm 0.00 *(0 / 6)$ \\
\hline
\end{tabular}

* denotes $p<0.05$ compared to colitis control, \# denotes $p<0.05$ compared to OFI + DSM I5I 58 group, OFI = Oligofructose and Inulin. Incidence of translocation is presented between parentheses as positive animals/total number of animals.

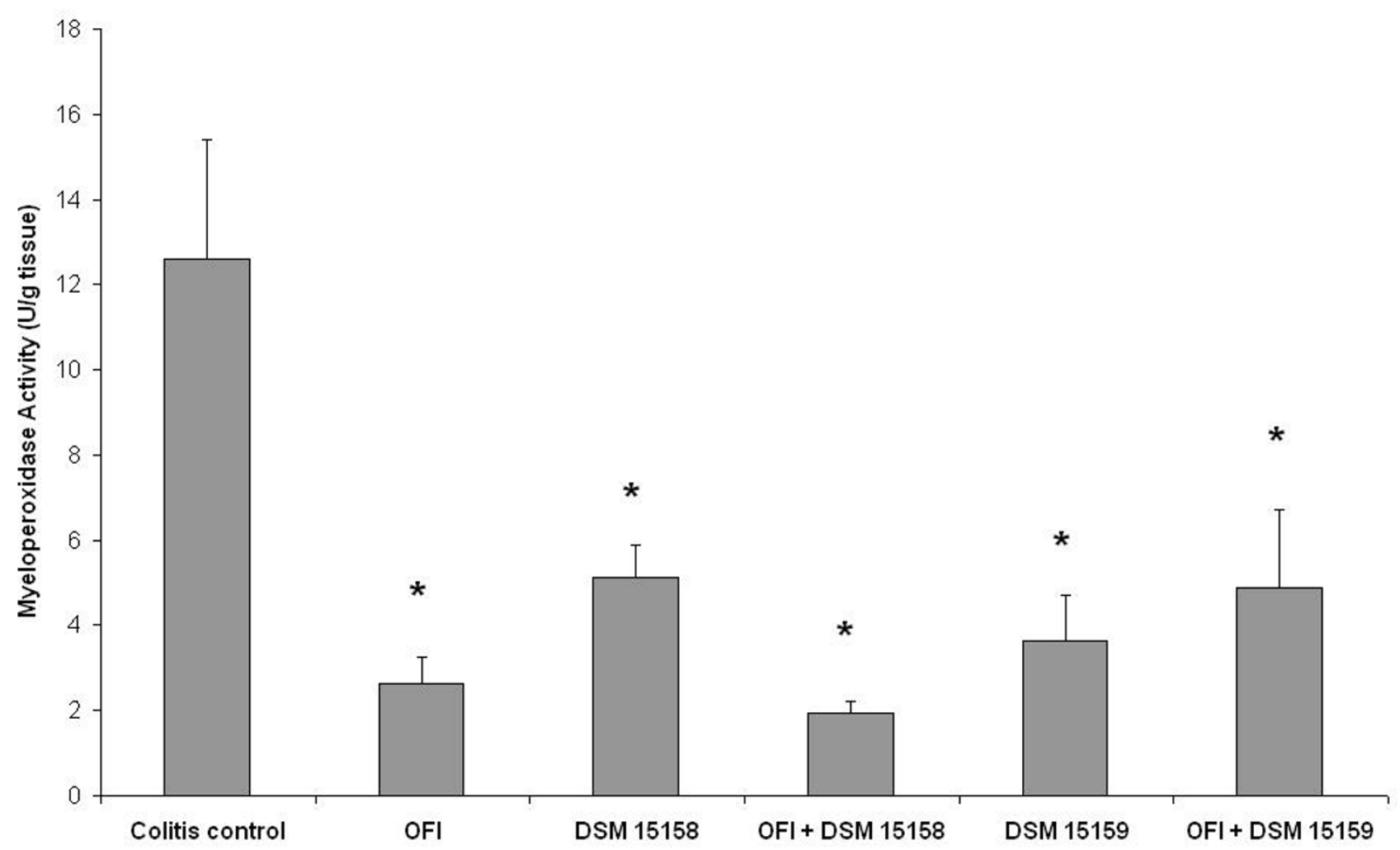

Figure 2

Colonic Myeloperoxidase Activities (U/g tissue). * denotes $\mathrm{p}<0.05$ compared to colitis control. 


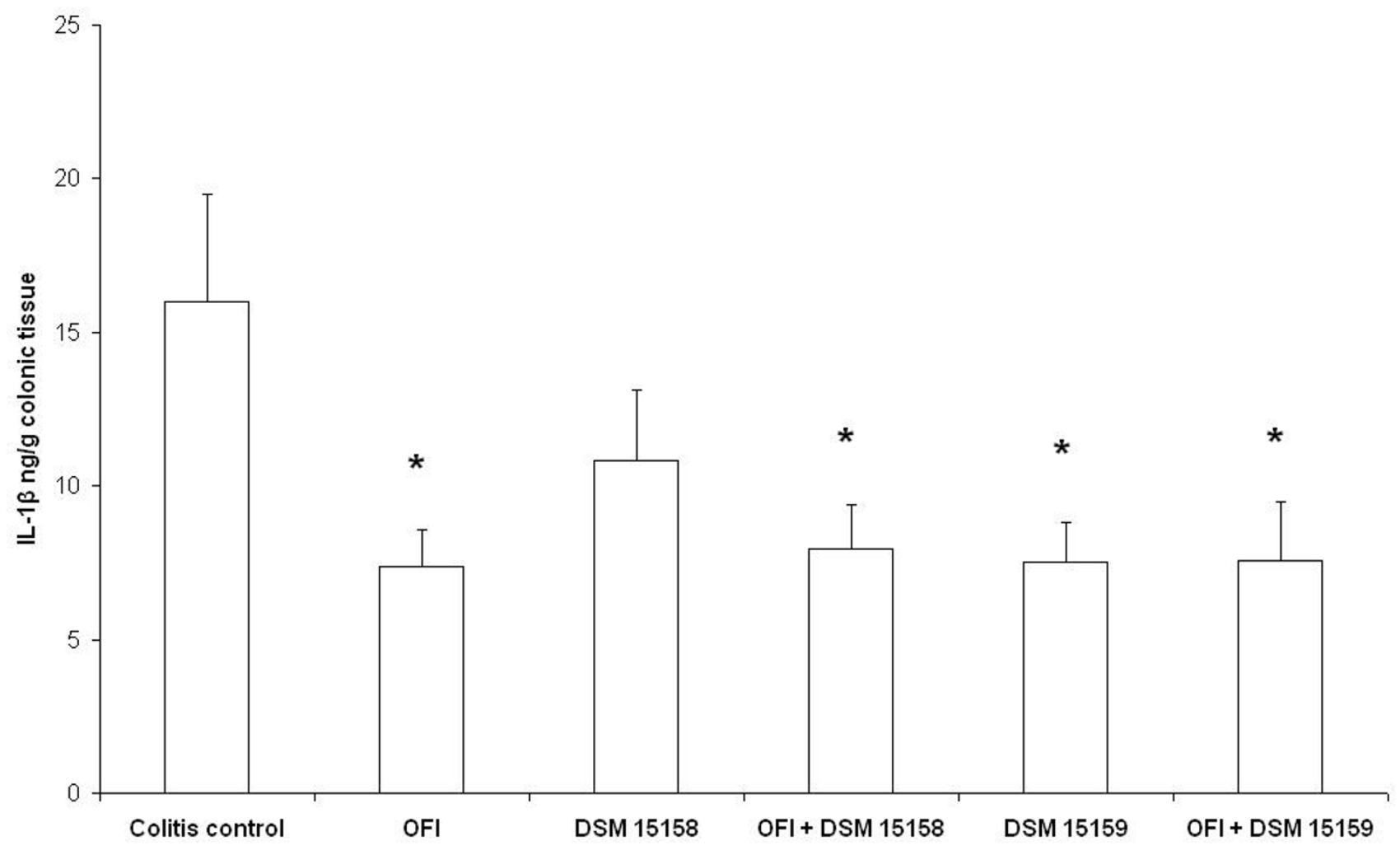

Figure 3

Colonic IL-I $\beta$ values (pg/g tissue). * denotes $p<0.05$ compared to colitis control.

induce IL-8 production, whereas the non pathogenic Gram-negative strain did in a dose-dependent way [23]. It has been shown that butyrate significantly inhibits Th1type responses and that this might explain the therapeutic effect of butyrate in IBD patients. Acetate and propionate have less marked modulatory actions, and in some cases have effects that oppose those of butyrate. A combination of the three SCFA causes a shift in the Thelper lymphocyte phenotype towards a more anti-inflammatory phenotype [24], and in this study we found that succinic acid increased significantly in OFI group with and without DSM 15159 compared to the colitis control and other groups and the sum values of propionic, butyric and succinic acid increased significantly in all treated groups compared to the colitis control group. However, this might explain that the protective effects of prebiotics and probiotics could be through the production of SCFAs.

The production of TNF- $\alpha$ was not detected in all our groups. We can not for sure conclude or suggest that TNF$\alpha$ has no role in intestinal inflammation. The lack of detection in our experiment could be due to the sensitivity of the ELISA kit. Also reports of this cytokine in inflamma- tory bowel disease IBD are somewhat contradictory, whereas some groups were able to demonstrate increased levels of TNF others were unable to detect it in patients with IBD (4). In another animal study, failure to detect local or systemic TNF and failure to prevent colonic inflammation with anti-TNF antiserum have pointed that TNF could not be an inflammatory mediator in DSSinduced murine colitis (25). IL-10 and TGF- $\beta$ were maintained in all groups and this suggests that mediators other than them are involved in the anti-inflammatory effects. These results are in agreement with a previous study [7]. On the other hand, studies of IL-10 levels in inflamed mucosa are not conclusive. Preliminary data from previous researchers indicate that a feed back loop may exist in IBD, in which an increased production of the cytokine interferon- $\gamma$ down regulates IL-10 production, therefore its level in the mucosa may be (although increased) not adequately high [26]. Topical IL-10 enema treatment of patients with ulcerative colitis unveiled that IL-10 is effective in down-regulating pro-inflammatory cytokine synthesis from IBD monocytes and lymphocytes both in vitro and in vivo [27]. In that study, equal concentrations of IL10 appear detectable in both normal and IBD intestinal 


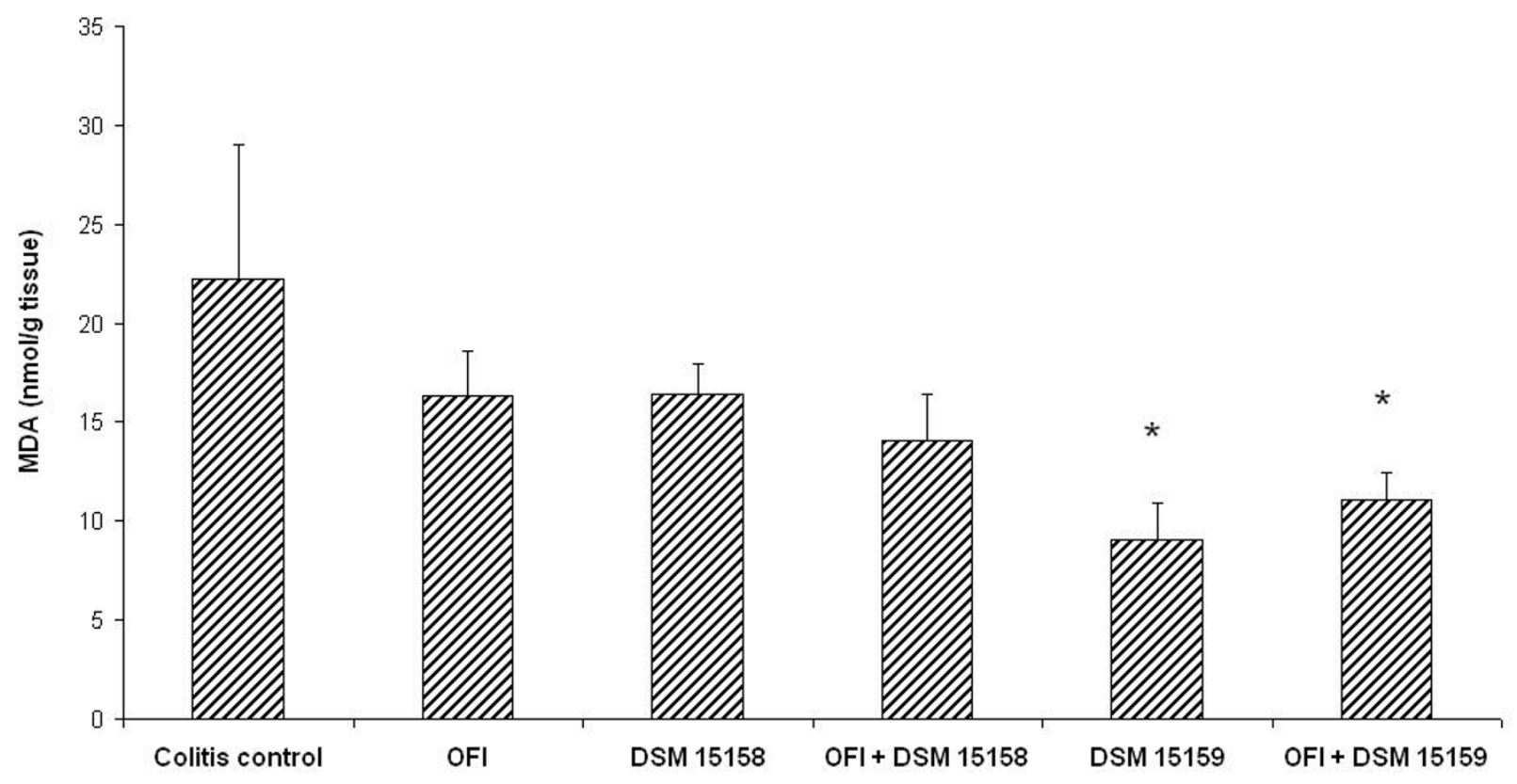

Figure 4

Malondialdehyde (MDA) concentration in the colon (nmol/g tissue). * denotes $\mathrm{p}<0.05$ compared to colitis control.

lamina propria biopsy homogenates. This seems surprising in view of other results $[28,29]$ also argue against a general deficiency in IL-10 production in IBD. They in fact observed an increase in IL-10 producing cells and rather suggest that in IBD the production of IL-10 is dislocated and insufficient to down-regulate pro-inflammatory cytokines in the lamina propria compartment. It has also bean shown that IL-10 gene therapy is therapeutic for dextran sodium sulfate-induced murine colitis [30].

Oxidative stress has been implicated in the pathogenesis of inflammatory bowel disease. Enhanced release of reactive oxygen species (ROS) plays an important role in the pathogenesis of clinical inflammatory bowel diseases. ROS are also involved in the pathogenesis of DSS-induced colitis [31]. In the IBD patients serum lipid peroxidation products were significantly elevated when compared to control subjects, suggesting the presence of increased oxidative stress consistent with inflammatory activity [32]. It has been shown that measurements of lipid peroxidation confirm previous evidence, indicating that development of colitis is associated with a significant burst in ROS [33]. We measured MDA in colonic tissues as an assessment of oxidative stress. We found significantly decreased levels of mucosal lipid peroxidation products in the $B$. infantis DSM 15159 groups with and without OFI compared to the colitis group. This is consistent with findings in other studies showing an increased in lipid peroxidation products with inflammation, both in Crohn's disease and ulcerative colitis [34]. We also found that there was increase in succinic acid in B. infantis DSM $15159+$ OFI group. Because of the $\mathrm{pH}$-depended inhibition of the res-

Table 2: SCFAs values ( $\mu \mathrm{mol} / \mathrm{g}$ cecal content) of all the experimental groups

\begin{tabular}{lllllll}
\hline SCFAs & Colitis Control & OFI & DSM I5I58 & OFI + DSM I5I58 & DSM I5I59 & OFI + DSM I5I59 \\
\hline Succinic & $0.0(0.0-1.1)$ & $4.5(2.9-5.7) *$ & $0.0(0.0-0.0) \# \S$ & $1.5(1.2-1.6) \# \S$ & $0.4(0.0-4.7) \# \S$ & $5.9(4.0-6.8) *$ \\
Propionic & $3.3(3.1-3.3)$ & $6.2(3.6-7.0)$ & $4.7(3.2-5.7)$ & $4.9(4.7-8.8)$ & $5.7(5.1-5.9)$ & $7.5(5.9-10.3)$ \\
Butyric & $2.3(0.0-8.4)$ & $5.5(4.2-7.6)$ & $6.8(6.4-13.7)$ & $3.3(3.1-6.2)$ & $5.7(3.9-6.8)$ & $5.9(3.3-10.0)$ \\
Acetic & $23.1(22.7-28.1)$ & $35.8(26.1-47.1)$ & $30.9(24.7-46.3)$ & $20.0(18.6-25.3)$ & $22.9(20.7-28.3)$ & $28.4(20.8-36.8)$ \\
Lactic & $0.0(0.0-0.0)$ & $1.6(0.0-3.2)$ & $2.5(2.4-3.0)$ & $0.4(0.0-1.1)$ & $0.4(0.0-1.0)$ & $2.0(0.0-2.8)$
\end{tabular}

* denotes $\mathrm{p}<0.05$ compared to colitis control; \# denotes $\mathrm{p}<0.05$ compared to OFI + DSM I5I59; $\S$ denotes $\mathrm{p}<0.05$ compared to OFI. Data presented as Median ( $25^{\text {th }}-75^{\text {th }}$ percentile) 
piratory burst by succinate [35], this increase could cause a significant reduction in $\mathrm{pH}$, thereby succinic acid may be by reducing $\mathrm{pH}$ further reduce neutrophils infiltration and the neutrophil respiratory burst [35].

B. infantis DSM 15159 with and without OFI increased significantly cecum lactobacilli count, which might suggest that the reduction of lipid peroxidation might also be caused by the formation of antioxidant factors by lactobacilli. Cecum bifidobacteria count increased significantly in OFI with and without $B$. infantis strains and this is probably due to the fact that bifidobacteria utilized OFI rapidly and increased in numbers. Wang et al (9) showed that oligofructose and inulin selectively stimulated growth of bifidobacteria. Bacterial translocation has been reduced by most of the groups to MLNs and liver. In MLNs the increased translocation in DSS-colitis decreased significantly in all treated groups. As for the liver, the translocation decreased significantly in all groups compare to the colitis group and OFI $+B$. infantis DSM 15158 groups. This reduction in bacterial translocation could be due to the reduction in the inflammation by the different mechanisms mentioned before. It seems that the translocation to the extraintestinal sites is affected by the administration of pre- and probiotic and this could be due to the effects on gastrointestinal tract, barrier functions and intestinal inflammation. These have been reflected by the reduction of IL-1 $\beta$, MPO and MDA in the intestinal tissue, and reduction of disease activity index.

\section{Conclusion}

Major differences in effect were observed between the two tested strains of $B$. infantis with regards to MDA, succinic acid concentration and translocation rate. The mechanisms by which probiotics, prebiotics and synbiotics work and affect the colitis induced by DSS could be through direct and indirect effects on microflora ecology, barrier functions and cellular proliferation, and production of different substances e.g. SCFAs, which could affect the local and systemic immunity and lipid peroxidation.

\section{Competing interests}

The authors declare that they have no competing interests. Dr Berggren is affiliated with Probi AB.

\section{Authors' contributions}

NO contributed in designing the study with other authors, performed experimental studies and analysis, data analysis, prepared and wrote the manuscript. DA study design contribution, performance of experimental studies, input to manuscript preparation. GM study design, co-ordination and supervision of the study, input to manuscript preparation. SA study design, co-ordination and supervision of the study, input to manuscript preparation. $\mathrm{AB}$ performance of SCFAs analysis. BJ study design, co-ordi- nation and supervision of the study, input to manuscript preparation.

\section{Acknowledgements}

This work has been carried out with financial support from the Commission of European Communities, specific RTD program Quality of Life and Management of Living Resources, QLRT-200I-00135, Functional Assessment of Interactions between the Human Gut Microbiota and the Host. It does not necessarily reflect the Commission's views and in no way anticipates the Commission's future policy in this area. This study was supported by grants from cancer foundation of Sweden. A. Påhlsson's Foundation, Ruth and Richard Juhlin's Foundation, Malmö University Hospital, Lundgren's Foundation, Gunnar Nilsson's Foundation and Einar \& Inga Nilsson's Foundation, Sweden.

\section{References}

I. Strober W, Fuss IJ, Blumberg RS: The immunology of mucosal models of inflammation. Annu Rev Immunol 2002, 20:495-549.

2. Sellon RK, Tonkonogy S, Schultz M, Dieleman LA, Grenther W, Balish $E$, Rennick DM, Sartor RB: Resident enteric bacteria are necessary for development of spontaneous colitis and immune system activation in interleukin- I0-deficient mice. Infec Immun I 998, 66( I I):5224-523I.

3. Guarner F, Malagelada JR: Role of bacteria in experimental colitis. Best Pract Res Clin Gastroenterol 2003, I 7(5):793-804.

4. Rogler G, Andus T: Cytokines in inflammatory bowel disease. World J Surg 1998, 22(4):382-9.

5. Kruidenier L, Verspaget HW: Oxidative stress as a pathogenic factor in inflammatory bowel disease-radicals or ridiculous? Aliment Pharmacol Ther 2002, I 6:1997-20I5.

6. Madsen KL, Doyle JS, Jewell LD, Tavernini MM, Fedorak RN: Lactobacillus species prevents colitis in interleukin 10 gene-deficient mice. Gastroenterol 1999, I | 6: I 107-I I |4.

7. McCarthy J, O'Mahony L, O'Callaghan L, Sheil B, Vaughan EE, Fitzsimons N, Fitzgibbon J, O'Sullivan GC, Kiely B, Collins JK, Shanahan F: Double blind, placebo controlled trial of two probiotic strains in interleukin 10 knockout mice and mechanistic link with cytokine balance. Gut 2003, 52:975-980.

8. Madsen K, Cornish A, Soper P, McKaigney C, Jijon H, Yachimec C, Doyle J, Jewell L, De Simone C: Probiotic bacteria enhance murine and human intestinal epithelial barrier function. Gastroenterol 200I, I 2 I:580-59I.

9. Wang X, Gibson GR: Effects of the in vitro fermentation of oligofructose and inulin by bacteria growing in the human large intestine. J Appl Bacteriol 1993, 75:373-380.

10. Osman N, Adawi D, Ahrne S, Jeppsson B, Molin G: Modulation of the effect of dextran sulfate sodium-induced acute colitis by the administration of different probiotic strains of Lactobacillus and Bifidobacterium. Dig Dis Sci 2004, 49(2):320-7.

II. Videla S, Vilaseca I, Antolin M, Garcia-Lafuente A, Guarner F, Crespo E, Casalots J, Salas A, Malagelada JR: Dietary inulin improves distal colitis induced by dextran sodium sulfate in the rat. Am J Gastroenterol 2001, 96(5): | 486-93.

12. Johansson ML, Molin G, Jeppsson B, Nobaek S, Ahrne S, Bengmark S: Administration of different Lactobacillus strains in fermented oatmeal soup: in vivo colonization of human intestinal mucosa and effect on the indigenous flora. Appl Environ Microbiol 1993, 59(I): I5-20.

13. Murthy SN, Cooper HS, Shim H, Shah RS, Ibrahim SA, Sedergran DI: Treatment of dextran sulfate sodium-induced murine colitis by intracolonic cyclosporin. Dig Dis Sci 1993, 38(9): I722-I734.

14. Cooper HS, Murthy SN, Shah RS, Sedergran DI: Clinicopathologic study of dextran sulfate sodium experimental murine colitis. Lab Invest 1993, 69(2):238-249.

15. Murthy S, Murthy NS, Coppola D, Wood DL: The efficacy of BAY y 1015 in dextran sulfate model of mouse colitis. Inflamm Res 1997, 46:224-233.

16. Rada $V$, Petr J: A new selective medium for the isolation of glucose non-fermenting bifidobacteria from hen caeca. J Microbiol Methods 2000, 43(2): 127-32. 
17. Matteuzzi D, Crociani F, Emaldi O: Amino acids produced by bifidobacteria and some Clostridia. Ann Microbial (Paris) 1978, | 29B(2): |75-8I.

18. Richardson AJ, Calder AG, Stewart CS, Smith A: Simultaneous determination of volatile and non-volatile acidic fermentation products of anaerobes by capillary gas chromatography. Lett Appl Microbiol 1989, 9:5-8.

19. Jensen MT, Cox RP, Jensen BB: Microbial production of skatole in the hind gut of pigs given different diets and its relation to skatole deposition in back fat. Anim Sci 1995, 61:293-304.

20. Furrie E, Macfarlane S, Kennedy A, Cummings JH, Walsh SV, O'neil DA, Macfarlane GT: Synbiotic therapy (Bifidobacterium longum/Synergy I) initiates resolution of inflammation in patients with active ulcerative colitis: a randomised controlled pilot trial. Gut 2005, 54(2):242-9.

21. Arai Y, Takanashi H, Kitagawa H, Okayasu I: Involvement of interleukin-I in the development of ulcerative colitis induced by dextran sulfate sodium in mice. Cytokine 1998, I0(I I):890-6.

22. Borruel N, Carol M, Casellas F, Antolin M, de Lara F, Espin E, Naval J, Guarner F, Malagelada JR: Increased mucosal tumour necrosis factor alpha production in Crohn's disease can be downregulated ex vivo by probiotic bacteria. Gut 2002, 5 I (5):659-64.

23. Lammers KM, Helwig U, Swennen E, Rizzello F, Venturi A, Caramelli E, Kamm MA, Brigidi P, Gionchetti P, Campieri M: Effect of probiotic strains on interleukin 8 production by HT29/19A cells. Am J Gastroenterol 2002, 97(5): I | 82-6.

24. Cavaglieri CR, Nishiyama A, Fernandes LC, Curi R, Miles EA, Calder PC: Differential effects of short-chain fatty acids on proliferation and production of pro- and anti-inflammatory cytokines by cultured lymphocytes. Life Sciences 2003, 73(13): 1683-1690.

25. Olson AD, DelBuono EA, Bitar KN, Remick DG: Antiserum to tumor necrosis factor and failure to prevent murine colitis. J Pediatr Gastroenterol Nutr 1995, 2 I (4):410-8.

26. Schreiber S: Experimental immunomodulatory therapy of inflammatory bowel disease. Neth J Med 1998, 53(6):S24-31.

27. Schreiber S, Heinig T, Thiele HG, Raedler A: Immunoregulatory role of interleukin- 10 in patients with inflammatory bowel disease. Gastroenterology 1995, 108: |434-| 444.

28. Gasche C, Bakos S, Dejaco C, Tillinger W, Zakeri S, Reinisch W: IL10 secretion and sensitivity in normal human intestine and inflammatory bowel disease. J Clin Immunol 2000, 20:362-370.

29. Autschbach F, Braunstein J, Helmke B, Zuna I, Schurmann G, Niemir ZI, Wallich R, Otto HF, Meuer SC: In situ expression of interleukin- 10 in noninflamed human gut and in inflammatory bowel disease. Am / Pathol 1998, I53:121-130.

30. Lindsay JO, Sandison A, Cohen P, Brennan FM, Hodgson HJ: IL-IO gene therapy is therapeutic for dextran sodium sulfateinduced murine colitis. Dig Dis Sci 2004, 49(7-8): 1327-34.

31. Araki $Y$, Andoh A, Fujiyama Y: The free radical scavenger edaravone suppresses experimental dextran sulphate sodiuminduced colitis in rats. Int I Mol Med 2003, I 2(I): I25-9.

32. Forrest CM, Gould SR, Darlington LG, Stone TW: Levels of purine, kynurenine and lipid peroxidation products in patients with inflammatory bowel disease. Adv Exp Med Biol 2003, 527:395-400.

33. Segui J, Gironella M, Sans M, Granell S, Gil F, Gimeno M, Coronel P, Pique JM, Panes J: Superoxide dismutase ameliorates TNBSinduced colitis by reducing oxidative stress, adhesion molecule expression, and leukocyte recruitment into the inflamed intestine. J Leukoc Biol 2004, 76(3):537-44.

34. Kruidenier L, Kuiper I, Lamers CB, Verspaget HW: Intestinal oxidative damage in inflammatory bowel disease: semi-quantification, localization, and association with mucosal antioxidants. J Pathol 2003, 20I(I):28-36.

35. Rotstein OD, Nasmith PE, Grinstein S: The Bacteroides by-product succinic acid inhibits neutrophil respiratory burst by reducing intracellular pH. Infect Immun 1987, 55(4):864-70.

\section{Pre-publication history}

The pre-publication history for this paper can be accessed here:

\section{http://www.biomedcentral.com/1471-230X/6/31/pre} pub
Publish with Biomed Central and every scientist can read your work free of charge

"BioMed Central will be the most significant development for disseminating the results of biomedical research in our lifetime. "

Sir Paul Nurse, Cancer Research UK

Your research papers will be:

- available free of charge to the entire biomedical community

- peer reviewed and published immediately upon acceptance

- cited in PubMed and archived on PubMed Central

- yours - you keep the copyright
BioMedcentral 